\title{
The use of dietary supplements by professional athletes.
}

\author{
Elina Petkova ${ }^{1}$, Kalin Ivanov ${ }^{2}$, Stanislava Ivanova ${ }^{2 *}$, Stanislav Gueorguiev ${ }^{1}$ \\ ${ }^{1}$ Department of Pharmaceutical Sciences, Faculty of Pharmacy, Medical University of Plovdiv, Plovdiv, Bulgaria \\ ${ }^{2}$ Department of Pharmacognosy and Pharmaceutical Chemistry, Faculty of Pharmacy, Medical University of Plovdiv, \\ Plovdiv, Bulgaria
}

\begin{abstract}
Professional athletes are exposed to everyday intensive physical strain. In order to provide for the energy demands of the organism, the athletes consume various food supplements. A specially designed questionnaire was used to convey an anonymous survey of a random sample of 66 professional athletes. The aim of the present research was to assess the intake of the most popular food supplements used in professional sport. The results of the survey confirmed that professional athletes are fully informed about the benefits provided by the intake of food supplements but were not well aware of the health risk hidden in some formulations and accepted them as safe products. Amino acids had the largest consumption rate among food supplements, followed by proteins, magnesium, creatine and others.
\end{abstract}

Keywords: Sport, Dietary supplements, Food supplements, Athletes, Professional sport.

Accepted on March 22, 2018

\section{Introduction}

Professional athletes are exposed to everyday intensive physical strain. In order to provide for the energy demands of the organism, the athletes consume various food supplements (FS) [1]. The substances incorporated in FS implemented in sports could be classified in two different large groups: ingredients banned by WADA and ingredients permitted for use $[2,3]$. In spite of the fact that the market offers numerous permitted supplementary products, marketed as FS, their administration is not absolutely safe and hides certain real risks for the sportsmen because the post-production FS quality and quantity control is not mandatory unlike that on medicinal products. This is the major factor underlying the alarming reports published by numerous researchers revealing undeclared substances in FS [4-13]. The lack of obligatory analytical control and the liberal regulation policy on FS can cause: incorporation of deliberately undeclared substances; accidental pollution during production (accidental mixing of banned substances and the supplement) or false products.

Most often the undeclared substances in FS are anabolic steroids, sibutramine $[14,15]$ and others that can cause serious health effects on the cardiovascular, central nervous, endocrine and genital system. The risk for the consumer of content of hormonal substances could be present in non-hormonal products, such as vitamins, minerals, amino acids and others, as the current registration and production regime is liberal. Qualitative and quantitative analyses are recommendable but not mandatory in practice. The consumers of this group of products are not protected because of the absence of analytical control.
The World Anti-Doping Code outlines that each athlete is obliged to ascertain that no banned substance has entered into his organism. $\mathrm{He} / \mathrm{she}$ is personally responsible for any banned substances found in his/her sample.

It is well known that $44 \%$ of the positive doping samples established by the UK Anti-Doping Organization follow the administration of food supplements containing banned ingredients. The Winter Olympic Games in Sochi evidenced 2631 doping tests, 7 of which showed a positive result. The athletes supported the thesis that those results were caused by intake of food supplements [16].

The above cited considerations focused our interest and attention on assessment of FS intake administered by our professional athletes.

The aim of the present research was to assess the intake of the most popular food supplements used in professional sport and to make a structural analysis of the phenomenon.

\section{Material and Methods}

A specially designed questionnaire was used to convey an anonymous survey in the period $1^{\text {st }}$ March 2017-1 ${ }^{\text {st }}$ May 2017 of a random sample of 66 professional athletes from the following sports-football, basketball, box, karate, kick box, MMA, judo, weight lifting, body-building, tennis, rowing, athletics and power-lifting. The survey covered 10 women and 56 men. The athletes answered 21 questions. The participation in the questionnaire survey was voluntary and anonymous. The sample was heterogeneous by age and education degree. Comparative, structural and graphic analyses were conducted. 


\section{Results and Discussion}

The age of the selected sample varied from 18 to $40 \mathrm{y}$, mean age $26.31 \mathrm{y}$. The prevailing disciplines were body building, tennis and power-lifting (Figure 1).

The average number of years of professional athletes' practice was $12.83 \mathrm{y}$. The longest practice was reported by tennis players-19.3 y, followed by body-builders-15.10 y, boxers-12.25 y and karate athletes-12.75 y. About $52 \%$ of the professional athletes, respondents to the survey practiced about 21-25 h per week. The data clearly showed that professional athletes were exposed to everyday intensive physical overstrain.

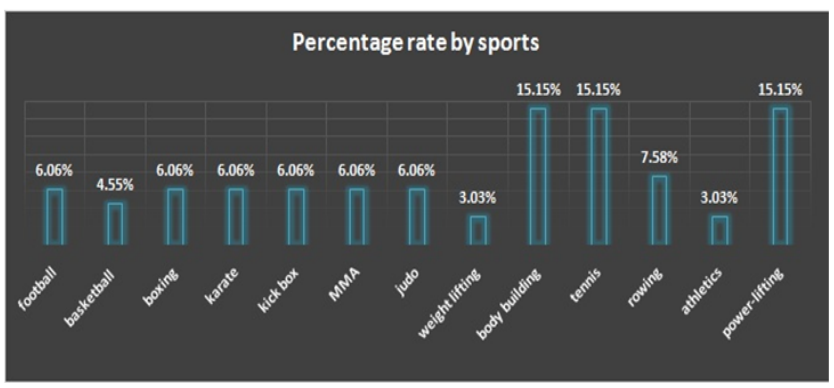

Figure 1. Respondents' rate by sport type.

All respondents were convinced that their diet was very important for their sports results and thus they had consumed food supplements during the past 6 months.

Amino acids had the largest consumption rate among FS-85\%; followed by proteins- $85 \%$; magnesium $-82 \%$ and creatine- $73 \%$. The intake of basketball players and boxers was almost the same. All of the studied basketball players consumed amino acids, proteins, creatine and magnesium. The same was the rate of boxers that included amino acids, proteins, creatine, magnesium and tribulus. $75 \%$ of boxers also take isotonic beverages.

The greatest number of food supplements was consumed by weight lifting athletes (10 types of FS daily). The supplements included glutamine, caffeine, FS for joints support, creatine, protein, magnesium and amino acids. Those FS were used by all inquired athletes $(100 \%)$ practicing this sport.

All (100\%) MMA, judo athletes and bodybuilders used creatine, protein, amino acids and magnesium.

The responding kick-boxers consumed creatine, protein, magnesium and amino acids every day. One fourth of them also used brewer's yeast, biotin, Leuzea root, yohimbine and multivitamins.

All karate athletes covered by this survey used magnesium. A great part of them-75\% also supplemented their diet with protein, tribulus and multivitamins.

The majority (90\%) of the tennis professionals drank isotonic solutions, magnesium, multivitamins and $10 \%$ of them reported consumption of testosterone stimulators.
Athletics professionals reported the smallest number of FS consumed (5 FS types per day), containing caffeine, protein, magnesium, Leuzea root and multivitamins.

All power-lifting athletes declared the use of protein and amino acids.

The large number of FS consumed by the athletes outlined the necessity of a more careful selection of the used formulations and more serious control on athletes' diet exercised by coaches and dieticians.

In order to fulfil the tasks of the survey it was important to answer the question "Where do athletes purchase their food supplements?" Healthy foods stores and stores for sports supplements were the most popular among FS consumers covered by our survey $(90.91 \%)$. The athletes' responses showed that the number of sports professionals preferring internet FS suppliers increased constantly at a high rate $(65.15 \%)$ and the number of those preferring pharmacies as a place to buy the preferred FS and consult a specialist was decreasing (16.67\%).

The published scientific evidence revealed that more and more patients suffered from undesired side effects due to FS intake, thus, the rate of side effects was also a target of our survey. The results showed that $13.64 \%$ of all inquired athletes had experienced undesired effects. The most frequent side effects were provoked by proteins $(67 \%)$, caffeine $(22 \%)$ and yohimbine $(11 \%)$. Proteins had caused irritation of the gastrointestinal tract and yohimbine and caffeine-tremor and elevated pulse rate.

Most used FS by professional athletes are presented on Figure 2 (results from total 66 respondents).

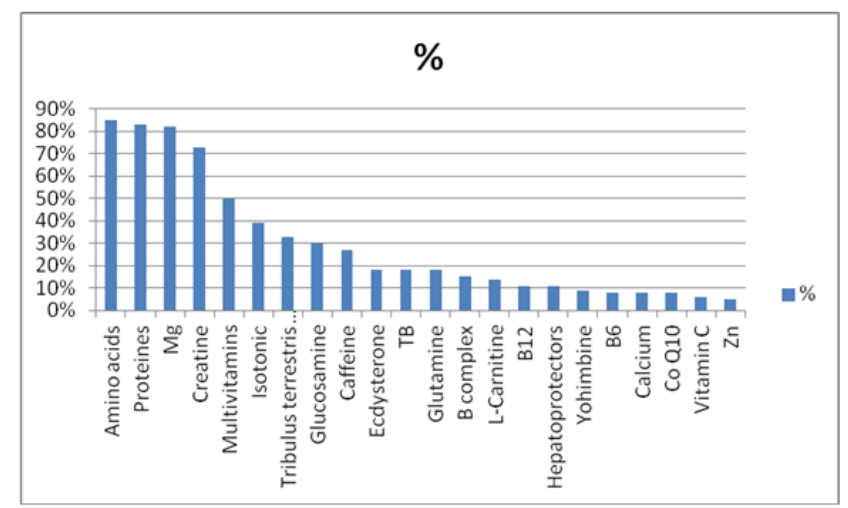

Figure 2. Most used food supplements by professional athletes.

The majority of professional athletes $(68.18 \%)$ supported the opinion that there was a health risk due to the presence of undeclared substances in the FS formulation. It is, though, alarming that one third of the respondents could not answer the question or were convinced that FS were absolutely safe for their health.

A substantial number of the respondents $(84.85 \%)$ have reported that they had access to information on anti-doping programs and prevention. The greatest share of the athletes 
(77.27\%) followed the instructions supplied by the sports dietician.

In order to satisfy the energy demands of the organism the athletes need to consume various food supplements and to follow a specific dietary regime enabling their quicker recovery in the time between exercises and competitions, to reduce fatigue and improve their performance.

\section{Conclusion}

The results of the survey confirmed that professional athletes consume large amounts of food supplements daily. We found that the athletes are fully informed about the benefits provided by the intake of those products but were not well aware of the health risk hidden in some formulations and accepted them as safe products. The lack of mandatory analytical control on FS could cause unfavourable health effects. The enhanced regulatory requirements to $\mathrm{FS}$ are of crucial significance for consumers' safety.

\section{References}

1. Ivanov K, Ivanova S. Substances in sports. Regul Toxicol Pharmacol 2016.

2. Justa Neves D, Caldas E. Dietary supplements: International legal framework and adulteration profile and characteristics of products on the Brazilian clandestine market. Regul Toxicol Pharmacol 2015; 73: 93-104.

3. https://www.wada-ama.org/

4. Ros JJ, Pelders MG, De Smet PA. A case of positive doping associated with a botanical food supplement. Pharm World Sci 1999; 21: 44-46.

5. Fouillot JP. Doping and dietary supplements. Bull Acad Natl Med 2004; 188: 933-942.

6. Pharmacy Times. Dietary supplement recall issued due to anabolic steroids. Practical Inform Pharm 2017.

7. Pharmacy Times. FDA warns of risky drugs in weight-loss supplements. Practical Inform Pharm 2015.

8. Geyer H, Parr MK, Mareck U, Reinhart U, Schrader Y, Schänzer W. Analysis of non-hormonal nutritional supplements for anabolic-androgenic steroids-results of an international study. Int J Sports Med 2004; 25: 124-129.
9. Geyer H, Braun H, Burke LM, Stear SJ, Castell LM. A-Z of nutritional supplements: dietary supplements, sports nutrition foods and ergogenic aids for health and performance. Br J Sports Med 2011; 45: 752-754.

10. Ivanova S, Ivanov K, Pankova S, Atanasov P, Obreshkova D, Petkova V. Analytical methods for the determination of non-labeled anabolic androgenic steroids supplements. World J Pharm Pharm Sci 2015; 4: 10-23.

11. Parr MK, Geyer H, Hoffmann B, Köhler K, Mareck U, Schänzer W. High amounts of 17-methylated anabolicandrogenic steroids in effervescent tablets on the dietary supplement market. Biomed Chromatogr 2007; 21: 164-168.

12. Geyer H, Parr M.K, Koehler K, Mareck U, Schänzer W, Thevis M. Nutritional supplements cross-contaminated and faked with doping substances. J Mass Spectrom 2008; 43: 892-902.

13. Kohler M, Thomas A, Geyer H. Confiscated black market products and nutritional supplements with non- approved ingredients analyzed in the Cologne Doping Control Laboratory 2009. Drug Test Anal 2010; 2: 533-537.

14. http://www.anti-doping.government.bg/bg/cat_66.html

15. Baume N, Mahler N, Kamber M, Mangin P, Saugy M. Research of stimulants and anabolic steroids in dietary supplements. Scandinavian J Med Sci Sports 2006; 16: 41-48.

16. Deijen J, Wientjes C, Vullinghs H, Cloin P, Langefeld J. Tyrosine improves cognitive performance and reduces blood pressure in cadets after one week of a combat training course. Brain Res Bull 1999; 48: 203-209.

\section{*Correspondence to}

Stanislava Ivanova

Department of Pharmacognosy and Pharmaceutical Chemistry

Faculty of Pharmacy

Medical University of Plovdiv

Plovdiv

Bulgaria 